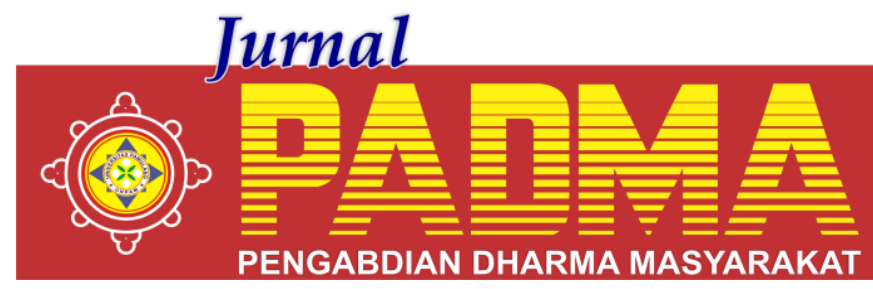

VOLUME 1, NOMOR 4, OKTOBER 2021

\title{
STRATEGI MANAJEMEN UNTUK MEWUJUDKAN KEMANDIRIAN YAYASAN ISLAM NURUL AMAL MELALUI PROGRAM WIRAUSAHA
}

\author{
${ }^{1}$ N. Sunardi, ${ }^{2}$ Chindera Setia Dewi Insani, ${ }^{3}$ Eris Martini, ${ }^{4 *}$ Evin Davinci Sagala, \\ ${ }^{5}$ Maman Surahman, ${ }^{6}$ Munawaroh \\ Universitas Pamulang, Tangerang Selatan, Banten, Indonesia \\ *evindavinci005@gmail.com
}

\begin{abstract}
Abstrak
Banyak dari masyarakat dan yayasan islam nurul amal yang belum memahami secara utuh tentang strategi dan kemandirian dalam berwirausaha. Perkembangan zaman membuat dunia usaha semakin berkembang dan membuat pelaku usaha harus lebih siap dalam persaingan dan kompetisi dan bisnis. Inovasi-inovasi bisnis menjadi faktor yang berpengaruh terdapap kemandirian dan keberlansungan dari suatu usaha, hal ini sangat terlihat dan terbuka dimasa saat ini yaitu masa dimana ekonomi dan dunia usahan turun akibat pandemi, hal ini membuat pelaku usaha harus berpikir kembali dan mengembangkan diri serta tenang menjadi sangat diperlukan dalam menghadapi pandemi COVID-19. Sekarang waktu yang tepat untuk menguji staregi yang sudah di bangun untuk memulai usaha dan akan terlihat kemandirian dari usaha tersebut. Tujuan dari pengabdian kepada masyarakat ini adalah untuk mengetahui bagaimana dari sisi bidang kewirausahaan di sektor pendidikan dan yayasan sebagai penopang untuk meneruskan kegiatan yang sebelumnya belum dilakukan atau sudah dilakukan namun belum maksimal ke arah yang lebih baik lagi untuk menunjang pertumbuhan dan perkembangan perekonomian di lingkungan yayasan maupun masyarakat sekitar. Hasil yang diperoleh dari pertemuan yang dilakukan dalam pengabdian kepada masyarakat bagaimana bidang kewirausahaan dalam dunia pendidikan dan ilmu dan pengalaman untuk dapat membuat suatu usaha yang maksimal dengan sistem manajemen bisnis yang baim dab tepat dan membentuk calon pelaku usaha yang memiliki mental dan sikap yang baik untuk melakukan atau memulai suatu usaha agar dapat berjalan dengan baik dan mampu menopang perekonomian mikro yang ada di lingkungan sekitar yayasan islam nurul amal.
\end{abstract}

Kata Kunci: Strategi, Kemandirian, Kewirausahaan, Yayasan Islam Nurul Amal

\begin{abstract}
Many of the people and Islamic foundations of Nurul Amal do not fully understand the strategy and independence in entrepreneurship. The times have made the business world more developed and made business actors have to be better prepared in competition and business. Business innovations are factors that influence the independence and sustainability of a business, this is very visible and open at this time, namely the time when the economy and the business world are down due to the pandemic, this makes business actors have to think again and develop themselves and calm down to be indispensable in the face of the COVID-19 pandemic. Now is the right time to test the strategies that have been built to start a business and you will see independence from the business. The purpose of this community service is to find out how from the aspect of entrepreneurship in the education sector and foundations as a support to continue activities that have not been carried out previously or have been carried out but have not been maximized in a better direction to support economic growth and development within the foundation and community. local communities. The results obtained from meetings held in community service are how the field of entrepreneurship in the world of education and knowledge and experience can make a maximum business with a good and appropriate business management system and form prospective business actors who have the mental and good attitude to do business. or starting a business so that it can run well and be able to support the micro-economy in the environment around the Nurul Amal Islamic Foundation
\end{abstract}

Keywords: Strategy, Independence, Entrepreneurship, Islamic Foundation Nurul Amal 


\section{PENDAHULUAN}

Munculnya persaingan dalam berwirausaha merupakan hal yang tidak dapat dihindari. Dengan adanya persaingan, maka wirausahawan di hadapkan pada berbagai peluang dan ancaman baik berasal dari dalam maupun dari luar lingkungan atau wirausaha lainnya yang akan memberikan pengaruh cukup besar terhadap kelangsunan hidup usaha. Untuk itu setiap wirausaha dituntut untuk selalu mengerti dan memahami apa yang terjadi di pasar dan apa yang menjadi keinginan konsumen serta berbagai perubahan yang ada di lingkungan bisnis, sehingga mampu bersaing dengan dunia bisnis lainnya dan berupaya untuk meminimalisir kelemahan-kelemahan dan memaksimalkan kekuatan yang di miliki. Kata "strategi" berasal dari bahasa Yunani "strategos", yang berasal dari kata stratos yang berarti militer dan Ag yang artinya pemimpin. Strategi dalam konteks awal diartikan sebagai generalship atau sesuatu yang dikerjakan oleh para jenderal dalam membuat rencana untuk menaklukan musuh dan memenangkan perang. Pada tahun 1950-an memperlihatkan masa perdamaian dan mulai muncul perusahaanperusahaan baru (Setiawan Hari P. dan Zulkieflimansyah, 1996). Pada awalnya konsep strategi didefinisikan sebagai berbagai cara untuk mencapai tujuan. Konsep generik ini terutama sesuai dengan perkembangan awal penggunaan konsep strategi yang digunakan dalam dunia militer (Ismail Solihin, 2012 ). Sementara Alfred Chandler berpendapat tentang strategi yang dikutip oleh Ismail Solihin, yang artinya bahwa "strategi adalah penentuan tujuan jangka panjang suatu perusahaan dan penerapan program tindakan serta alokasi sumber daya yang diperlukan untuk melaksanakan tujuan-tujuan ini." Jadi kata strategi digunakan untuk memenangkan sebuah pertarungan. Dalam hal ini, strategi yang digunakan oleh Yayasan Pendidikan Islam Nurul Amal dapat memenangkan persaingan dengan Lembaga atau Yayasan sejenis.

Menurut Gordon, yang dikutip oleh Kaswan dan Ade Sadikin, bahwa kewirausahan adalah memulai dan mengelola bisnis dengan inisiatif dan resiko besar, untuk memperoleh keuntungan (Kaswan dan Ade Sasangka, 2015). Sedangkan, kewirausahaan sosial digunakan untuk menjelaskan semua program ekonomi yang melayani misi sosial atau misi lingkungan hidup, serta yang menginvestasika ulang sebagian besar surplusnya dalam mendukung misinya. Meskipun belum terdapa definisi yang baku dan batasan-batasanya belum jelas. Namun, fokusnya pada efisiensi ekonomi dan inovasi sosial, yang terjadi pada konteks ketidakpastian yang sangat besar pada masa depan. Wirausaha sosial mengidentifikasi peluang untuk mendorong perubahan di masyarakat agar dapat memecahkan masalah sosial baru, dengan memberikan gagasan bar dan menyediakan jenis-jenis jasa atau pelayanan baru dan dengan mencari perpaduan baru atau yang lebih efisien dari sumber daya. Oleh karena itu, biasanya kewirausahaan sosial juga dikaitkan dengan inovasi sosial. Misalnya seperti Yayasan Pendidikan Islam Nurul Amal. Dari permasalahan diatas, adanya kebutuhan dari suatu permasalahan di sebuah sekolah Yayasan Pendidikan Islam Nurul Amal, maka kami selaku Mahasiswa yang berjumlah 5 orang mahasiswa dari pascasarjana Universitas Pamulang bermaksud menjalankan pengabdian kepada masyarakat sebagai wujud kami dalam menjalankan TRIDRAMA Perguruan Tinggi sekaligus menyelesaikan tugas perkuliahan mahasiswa S2 Manajemen Universitas Pamulang. YAYASAN PENDIDIKAN ISLAM NURUL AMAL (YPINA) berdiri sejak tahun 1997 didirikan oleh Almarhum H. Syatiri Bin H. Masan dengan akta Notaris No.06 Tanggal 02 April 1997 dan Beralamat di Jl. Selada II Rt 004 / Rw 011 Kelurahan Pondok Cabe Ilir 
Kecamatan Pamulang Kota Tangerang Selatan Provinsi Banten. YAYASAN PENDIDIKAN ISLAM NURUL AMAL (YPINA) ini didirikan diatas lahan $2000 \mathrm{M}^{2}$ didasarkan dengan niat tulus ikhlas dengan harapan besar pendiri Yayasan juga harapan masyarakat lingkungan sekitar bahwa YPINA dapat berperan dan berkiprah dalam dunia Pendidikan, keagamaan, akhlaq dan bidang kemanusiaan dengan Visi Misi mewujudkan Pendidikan yang berbasis karakter dengan mengedepankan Pendidikan Agama dan akhlak, berkarakter, peduli lingkungan dan berwawasan global. Awal mula pada tahun 1991-1996 lembaga ini menyelenggarakan kegiatan pendidikan jenjang Taman Pendidikan Al-qur'an dan Majlis Taklim dimana kegiatan ini dilkasanakan di ruang Musholla kemudian pada tahun 1997 pendidkan dikembangkan ke jenjang TK Islam Terpadu Nurul Amal dengan keadaan sarana hanya 2 lokal dengan jumlah murid pada waktu itu 45 peserta didik.

Dengan berbagai masukan dari masyarakat juga wali murid yang menginginkan agar diselenggarakan Sekolah Dasar, maka pada tahun 2005 kembali mengembangkan Pendidikan ke jenjang SD Islam Terpadu Nurul Amal disinilah Yayasan mulai berkembang pesat yang pada mulanya jejang SD dilaksanakan KBM hanya 2 lokal kelas dan tiap tahun bertambah 2 lokal kelas hingga saat ini berjumlah 24 lokal kelas . dengan jumlah siswa 635 siswa dan sarana dilengkapi dengan Masjid, lab. bahasa, perpustakaan ruang UKS , sarana olah raga dan lapangan parkir. Tahun 2020 yayasan ini melanjutkan jenjang Sekolah Menengah Pertama Islam Terpadu (SMP-IT) Islamic Boarding School dengan model pembelajaran berbasis Pendidikan pesantren dengan awali sarana 2 lokal asrama dan 2 lokal kelas hingga saat ini masih terus mengembangkan pembangunan.

Perguruan Tinggi di Indonesia mempunyai tiga tugas, salah satunya dalam memberikan kebermanfaatan untuk masyarakat yang membutuhkan keilmuan yang di miliki oleh Perguruan Tinggi dalam segala bidang. Kebermanfaatan untuk masyarakat dapat diwujudkan dalam bentuk pendampingan atau memberikan ilmu pengetahuan yang dibutuhkan oleh Masyarakat. Universitas Pamulang adalah salah satu Perguruan Tinggi yang ada di Kota Tangerang Selatan dengan dosen dan mahasiswa dengan jumlah yang cukup besar. Hal ini akan menjadikan peluang bagi masyarakat bisa mendapatkan kebermanfaatan karena adanya sumber daya yang dimiliki oleh Universitas Pamulang. Univeritas Pamulang bekerja sama dengan Yayasan Pembangunan Masyarakat Sejahtera untuk melakukan pengabdian kepada masyarakat dengan memberikan pendampingan dalam memberikan penyuluhan materi yang berkaikan dengan strategi manajemen untuk mewujudkan kemandirian Yayasan melalui kewirausahaan.

\section{METODE}

Metode yang digunakan dalam pelaksanaan PKM ini adalah pelatihan kepada guru di Yayasan Pendidikan Islam Nurul Amal. Dalam hal ini maka dalam pelaksanaan bimbingan teknis kepada 20 peserta di Yayasan Pendidikan Islam Nurul Amal dilakukan dengan metode sebagai berikut:

1. Penyampaian materi berupa powerpoint

2. Tanya jawab/Diskusi

Untuk melihat dan mengetahui keberhasilan dari bimbingan teknis, maka dilakukan evaluasi. Menurut Mathis dan Jackson (2002: 31) evaluasi pelatihan adalah membandingkan hasil-hasil setelah pelatihan dengan tujuan. Dalam hal ini evaluasi dilakukan melalui kuesioner, sebagai berikut: 
Tabel 1. Skala Likert

\begin{tabular}{|c|c|c|}
\hline No & Alternatif Pilihan Jawaban & Skor \\
\hline 1 & Sangat Setuju ( SS ) & 5 \\
\hline 2 & Setuju ( S) & 4 \\
\hline 3 & Ragu-Ragu ( RR ) & 3 \\
\hline 4 & Tidak Setuju ( TS ) & 2 \\
\hline 5 & Sangat Tidak Setuju ( STS ) & 1 \\
\hline
\end{tabular}

Sumber: Sugiyono ( 2016: 93)

Untuk mengetahui rentang skala ratarata skor jawaban peserta terhadap kuesioner maka dapat dihitung dengan cara: Rentang skala $=$ (skala terbesar - skor terkecil )/ skor terbesarDiketahui:

Skor terbesar $=5$ dan skor terkecil 1 , Maka rentang skala adlah 0,8 yaitu di dapat dari $(5-1) / 5=4 / 5=0,8$

Tabel 2. Rentang Inverval Skor

\begin{tabular}{|c|c|c|c|}
\hline Jawaban & Bobot & $\begin{array}{c}\text { Rentang } \\
\text { Interval } \\
\text { skor }\end{array}$ & Kategori \\
\hline $\begin{array}{c}\text { Sangat Setuju } \\
\text { (SS) }\end{array}$ & 5 & $\begin{array}{c}4,20- \\
5.00\end{array}$ & $\begin{array}{c}\text { Sangat paham } \\
\text { (SP) }\end{array}$ \\
\hline Setuju (S) & 4 & $\begin{array}{c}3,40- \\
4,20\end{array}$ & Paham (P) \\
\hline $\begin{array}{c}\text { Ragu-Ragu } \\
\text { (RR) }\end{array}$ & 3 & $\begin{array}{c}2,60- \\
3,40\end{array}$ & $\begin{array}{c}\text { Cukup Paham } \\
\text { (CP) }\end{array}$ \\
\hline $\begin{array}{c}\text { Tidak Setuju } \\
\text { (TS) }\end{array}$ & 2 & $\begin{array}{c}1,80- \\
2,60\end{array}$ & $\begin{array}{c}\text { Tidak Paham } \\
\text { (TP) }\end{array}$ \\
\hline $\begin{array}{c}\text { Sangat tidak } \\
\text { Setuju (STS) }\end{array}$ & 1 & $\begin{array}{c}1,00- \\
1,80\end{array}$ & $\begin{array}{c}\text { Sangat tidak } \\
\text { Paham (STP) }\end{array}$ \\
\hline
\end{tabular}

Sumber diadopsi dari Sugiyono ( 2016: 133)

Setelah dilakukan pengisian angket kuesioner oleh peserta pelatihan pada saat pelatihan telah berakhir maka Tim PKM mengumpulkan kembali angket yang telah dijawab oleh peserta pelatihan tersebut, yang kemudian seluruh jawaban responden diolah dan dianalisa.

\section{HASIL DAN PEMBAHASAN}

Kegiatan pengabdian ini dilaksanakan di Yayasan Pendidikan Islam Nurul Amal yang diikuti oleh Pengurus Yayasan, peserta didik, tenaga pendidik/kependidikan, orang tua peserta didik, komite sekolah bahkan kepada masyarakat sekitar lingkungan sekolah maupun umumnya masyarakat luas. Kegiatan ini dilaksanakan selama 1 hari. Dengan metode seminar dan dialog yang membahas tentang strategi manajemen untuk mewujudkan kemandirian yayasan melalui

program wirausaha. Anggota yayasan dihadapkan dengan permasalahan kemudian diminta untuk menyelesaikanya, dan anggota yayasan diajarkan untuk menggunakan logika berfikirnya dengan cara reflektif thinking, menganalisa apa yang dilihat, didengar dan dirasakan kemudian mengambil langkah yang tepat sebelum dikomunikasikan atau dihadirkan.

Materi yang disampaikan kepada anggota yayasan adalah sebagai berikut:

1. Mencari informasi peluang usaha, menghitung seberapa besar peluang usaha tersebut dan menentukan usaha yang akan diambil.

2. Memaksimalkan usaha yang sudah ada/ yang sudah dimiliki.

3. Mencari solusi menghadapi kendala yang dihadapi saat memulai usaha.

4. Membuat strategi manajemen dalam kewirausahaan sehingga menciptakan usaha yang sukses.

Berdasarkan materi yang disampaikan, setiap anggota yayasan dapat mengimplementasikan dan memulai usaha secara mandiri dengan strategi yang didapat. Dari usaha kecil yang memiliki peluang hingga usaha besar yang membutuhkan modal besar.

Berdasarkan hasil Analisis Deskriptif atas jawaban peserta PKM terhadap materi tersebut, menunjukkan sebagai berikut:

1. Terkait tentang pemahaman peserta terhadap strategi pengembangan usaha yang sudah ada mencapai 3,25 dengan katagori cukup paham. Hal ini berarti pengembangan usaha pada sector usaha yang sudah ada sebelumnya penting untuk dilakukan agar mendapat hasil yang maksimal. 
2. Terkait tentang pemahaman peserta terhadap menghitung dan melihat peluang usaha mencapai 4,15 dengan katagori paham. Hal ini berarti peserta memahami peluang yang ada di sekitar dan mampu mengimplementasikan ilmu yang telah di terima.

3. Terkait tentang pemahaman peserta tentang penyelesaian permasalahan/ kendala dalam usaha mencapai 3,55 dengan katagori paham. Hal ini dapat disimpulkan bahwa peserta memahami strategi maupun teori dalam menyelesaikan segala permasalahan yang akan timbul di dunia usaha

4. Terkait dengan pemahaman peserta membuat strategi dalam manajemen usaha mencapai 4,45 dengan katagori sangat paham. Hal ini dapat dikategorikan bahwa peserta sudah siap dan mampu untuk melaksanakan atau membuat suatu usaha dengan sistem manajemen yang tepat.

5. Terkait dengan pemahaman peserta mengenai mental dan kesiapan materil untuk membuat usaha mencapai 4,10 dengan katagori paham. Hal ini berarti peserta mampu memperkirakan kesiapan fisik maupun material serta mental dalam melaksanakan suatu usaha yang akan di mulai atau di kembangkan.

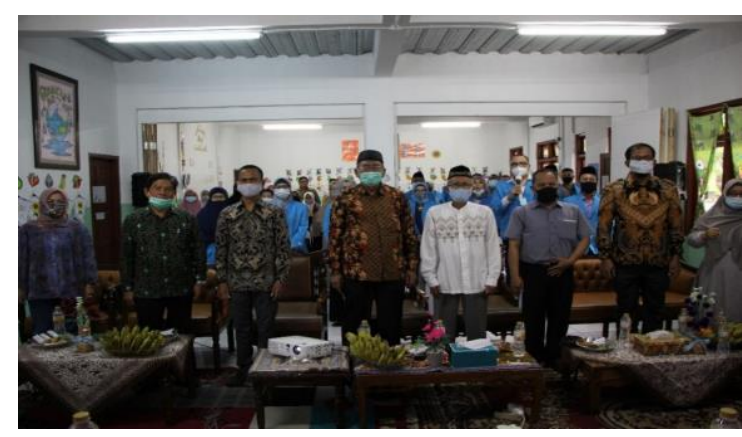

Gambar 1. Kehadiran Dosen Pembimbing PKM

\section{PENUTUP}

\section{KESIMPULAN}

Kesimpulan dalam pelaksanaan kegiatan Pengabdian Kepada Masyarakat oleh Universitas Pascasarjana Pamulang yang dilakukan oleh kelompok dua telah berjalan dengan lancar dan mendapat sambutan hangat dari tempat pelaksanaan kegiatan ini yaitu pihak Yayasan Pendidikan Islam Nurul Amal Pondok Cabe Ilir, Pamulang, Tangerang Selatan. Dengan adanya seminar dan dialog dalam pelaksanaan kegiatan Pengabdian Kepada Masyarakat ini harapan kami dapat memberikan pengetahuan dan membantu para pengurus YPINA maupun kepada Tenaga Pendidik/Kependidikan sehingga dapat membuat strategi manajemen kemandirian berwirausaha.

\section{SARAN}

Pelaksanaan kegiatan Pengabdian Kepada Masyarakat oleh Universitas Pascasarjana Pamulang yang dilakukan oleh kelompok dua mungkin masih terdapat kekurangan, untuk itu kritik, saran maupun masukan yang sifatnya membangun dari semua pihak demi perbaikan dan kebaikan untuk kemaslahatan bersama sangat kami harapkan. Semoga kegiatan pengabdian masyarakat ini juga dapat bermanfaat bagi YPINA dan masyarakat sekitar lingkungan Universitas Pascasarjana Pamulang juga masyarakat luas pada umumnya.

\section{DAFTAR PUSTAKA}

Setiawan Hari P. dan Zulkieflimansyah. (1996). Manajemen Strategi. Fakultas Ekonomi Universitas Indonesia,Jakarta Ismail Solihin. (2012). Manajemen Strategik. Jakarta: Erlangga

Kaswan dan Ade Sadikin Akhyadi. (2015).

Socil entrepreneurship: mengubah masalah sosial menjadi peluang usaha. Bandung: Alfabeta

Napa J. Awat, (1986). Manajemen Strategi. Yogyakarta: Liberty

Suhendri dan Idra Sasangka, (2014). Pengantar Bisnis. Bandung: Alfabeta. 